\title{
ВОПРОСЫ СТОРОН В ДОПРОСЕ ПО УСТАВУ УГОЛОВНОГО СУДОПРОИЗВОДСТВА
}

Аннотация: В статье исследованы нормативные правила фрормулирования и использования сторонами вопросов в допросах при производстве по уголовным делам. Основное внимание обращено на процедуры формулирования и использования вопросов сторонами (государственным обвинителем, защитником) подсудимому, сведущим лицам, свидетелям. В статье описаны: а) процедуры, определяющие очередность постановки вопросов подсудимому, сведущим лицам, свидетелям; б) процедуры использования свободного рассказа свидетелем в качестве базы для постановки вопросов; в) классификационные виды вопросов, выделяемых законодателем в Уставе уголовного судопроизводства 1864 г. Основным методом исследования является сравнение норм Устава уголовного судопроизводства 1864 г. и Уголовно-процессуального кодекса РФ 2001 г. Научная новизна статьи сводится к выявлению актуальных для действующего уголовно-процессуального закона норм Устава уголовного судопроизводства 1864 г., которые могут быть использованы в совершенствовании норм действующего уголовно-процессуального закона, касающегося формулирования и использования вопросов сторонами в допросах, по состязательному типу.

Ключевые слова: уголовный процесс, судебное следствие, допрос, вопрос, сторона, подсудимый, потерпевиий, свидетель, эксперт, специалист.

DOI: 10.7256/1994-1471.2014.4.11291

$\mathrm{Y}$ став уголовного судопроизводства 1864 г. (далее - УСС), несмотря на то, что он является результатом законотворческой деятельности второй половины XIX в., является источником актуальных нормативных идей, которые можно реализовать и в действующем Уголовно-процессуальном кодексе РФ 2001 г. (далее - УПК РФ). Прежде всего, привлекают внимание нормативные модели формулирования и использования сторонами вопросов в допросах, созданные авторами УСС.

Конструкция действующего УПК может представляться парадоксальной. В ней относительно допросов в первую очередь излагаются процессуальные результаты (показания) и лишь во вторую очередь нормативные модели допросов (процессуальных средств). При этом вопросам, как процессуальным средствам допроса, внимания, по нашему мнению, уделяется достаточно мало. Юридическая конструкция действующего УПК, вероятно, использовала традицию советского периода, реализованную в Уголовно-процессуальный кодекс РСФСР 1960 г. Но типы уголовного процесса, которые представляли и представляют УПК РСФСР и УПК РФ - различны, соответственно, вопроснодопросные нормативные модели участников в них должны различаться. В то же время состязательные модели УСС и УПК РФ, по заложенным в них законотворческим идеям, видятся близкими, позволяя искать путь для оценки ныне действующего уголовно-процессуального закона de lege ferenda с использованием УСС.

Первое, что видится важным для рассматриваемой темы, то это реализация в УСС принципа (общего условия) устности в судебном разбирательстве по уголовным делам. Устность, в противоположность письменности, образует одну из существенных черт уголовного процесса, построенного по принципу состязательности. Наоборот, использование в качестве опоры для типа уголовного процесса норм письменного, есть проявление розыскного (следственного) типа уголовного процесса. Относительно УСС приведенный тезис разрешается однозначно в пользу состязательного вектора регулирования уголовно-процессуальной деятельности сторон и суда.

Нормативным правилом ст. 625 УСС предусматривается, что судебное следствие производится устно и из этого правила допускаются только те исключения, которые прямо указаны в иных статьях УСС. Из этого нормативного правила возникают следующие логические следствия:

(C) Зашляпин Леонид Александрович

* Кандидат юридических наук, доцент кафедры конституционного и муниципального права, СанктПетербургский государственный политехнический институт

[leonid.zashlyapin@gmail.com]

195251, Россия, г. Санкт-Петербург, ул. Политехническая, д. 29. 
а) общим правилом судебного следствия является устная форма деятельности всех участников судебного разбирательства;

б) профессиональные и непрофессиональные представители сторон обвинения и защиты в уголовном процессе должны использовать устную форму в качестве доминирующей;

в) общее условие (принцип) об устности судебного следствия гармонично вербальным формам судебных действий - допросам.

Поддержание нормативного правила об устности являлось заботой вышестоящих судебных инстанции Российской империи. Согласно решению № 952, принятому Уголовным кассационным департаментом Правительствующего Сената, устность является существенным условием производства по уголовному делу в судебных заседаниях и из этого правила допускаются только те изъятия, которые указаны в законе. Очевидно, что кассационная инстанция удерживала правоприменителя на тех позициях, которые исключали иные толкования уголовно-процессуального закона и придание нормам закона значений, отсутствующих в УСС.

Другим решениями, принятыми Правительствующим Сенатом в начале действия УСС, когда наиболее важно было донести до российского правоприменителя суть нормативных идей законотворца, меняя правосознание правоприменителя с розыскного на состязательное отношение к ведению уголовных дел, представленное в решениях № 28 за 1867 г., № 575 за 1868 г., № 952 за 1869 г., определялось, что изъятия из общего условия об устности судебного разбирательства допускались только в точных пределах, обозначенных в нормах ст. 626629 УСС. Примечательно, что все эти исключения - возможные формы нормативного регулирования статуса и деятельности свидетелей и сведущих людей в уголовном процессе, но не профессиональных представителей сторон. Для прокурора и защитника в уголовном процессе (сторон) устность являлась правилом, не допускающим исключений.

Перед тем как перейти к сравнению регулирования устности по действующему уголовно-процессуальному закону зафиксируем, что в юридической технике, использованной авторами УСС при его создании, не использовались наименования статей. В связи с этим все то, что касалось устности, было нормативным содержанием диспозиций регулятивных норм, образовывало правило уголовно-процессуальной деятельности сторон, не могло быть зоной нормативных идей, деклараций, не нашедших надлежащей реализации в законе.

В УПК РФ устность может связываться с нормами ст. 240. Во всяком случае, наименование статьи «непосредственность и устность» пред- полагает это. К сожалению, все нормативное содержание частей 13 данной статьи не содержит упоминание устности в диспозициях действующих норм. Устность как общее условие нами интерпретируется из наименования статьи и содержания иных норм УПК РФ, регулирующих процедуры производства судебных действий и принятия процессуальных решений в ходе судебного разбирательства. Получается, что прямое включение авторами УСС правила об устности в диспозицию нормы ст. 625 УСС может быть более гармоничным с правилом ст. 123 Конституции РФ о состязательности уголовного судопроизводства, чем нормативное содержание ст. 240 УПК РФ. Любая интерпретация не исключает искажения воли законодателя, дискреционность в толковании правила сторонами и судом, произвол в правоприменительной практике.

В связи с изложенным, можно сформулировать промежуточное суждение о том, что общая нормативная среда для формулирования и использования вопросов сторон в допросах, в УСС видится более гармоничной, чем в УПК РФ.

Второе, что необходимо рассмотреть в настоящей статье, это само регулирование процедур формулирования и использования вопросов как процессуальных средств ведения допроса сторонами. В связи с этим в УСС видим следующие, корреспондирующиеся с рассмотренной выше ст. 625, нормативно-юридические конструкции.

Прежде всего, мы обращаем в наших работах по рассматриваемой теме внимание на нормы ст. 630 УСС, в которых стороны в уголовном судопроизводстве (прокурор, частный обвинитель, подсудимый, защитник) обозначаются как пользующиеся в судебном состязании одинаковыми правами. При этом обеим сторонам предоставляется право задавать свидетелям и сведущим лицам, с разрешения председательствующего, свои вопросы, использовать иные процедуры, касающиеся формулирования вопросов и их использования в допросах. De jure состязательность представляется в УСС через использование вопросной компетенции сторон, что весьма логично.

В этом случае мы видим тот же прием юридической техники, что и относительно общего условия об устности. Принцип состязательности (требование построения уголовного процесса по состязательному типу) в УСС присутствует в законе не обособленно от регулирования процессуального действия, а непосредственно в диспозиции нормы ст. 630, определяя правило о равенстве сторон в формулировании и использовании вопросов в допросах. Возникает юридическая конструкция «устность - состязательность - вопросы сторон участникам 
процесса», которая может рассматриваться как некоторая нормативная целостность, уголовно-процессуальный институт.

В этом уголовно-процессуальном институте необходимо выявлять свободу использования вопросов как процессуальных средств ведения допроса сторонами и нормативные ограничения этой свободы, образующие реальное субъективное право сторон. Юридико-технологический алгоритм проведения допросов (формулирования и использования вопросов) сторонами определялся следующими положениями.

1. Вопросы подсудимому возможны, в силу правила ст. 680 УСС, если он признавал свою вину. Только в этом случае председательствующим ему предлагались дальнейшие вопросы, относящиеся к обстоятельствам преступления, в котором он обвиняется.

Более того, вопросы подсудимому не связывались с процессуальной компетенцией сторон. Как было зафиксировано в ст. 683 УСС, подсудимого, не признающегося в преступлении, председатель суда при рассмотрении каждого доказательства спрашивает, не желает ли он в оправдание свое представить какие-либо объяснения или опровержения. В связанной с приведенной ст. 684 УСС определялось, что сверх того председатель и с его разрешения члены суда непосредственно, а присяжные заседатели - чрез председателя суда, могут предлагать подсудимому вопросы по всем обстоятельствам дела, представляющимся им недостаточно разъясненными. В диспозитивных правилах обеих статей не упоминается ни сторона обвинения, ни сторона защиты.

Отмеченная особенность нормативного регулирования оказалась в зоне внимания вышестоящей инстанции. В решении Уголовного кассационного департамента Правительствующего Сената № 1035 от 12 ноября 1869 г. по делу Неприемниковой было указано, что «право предлагать подсудимому, признающему свою вину, дальнейшие вопросы предоставлено упомянутой статьей председателю, который при этом не может быть стеснен чьими-либо указаниями на то, какие именно предлагать подсудимому вопросы. Прокурор, если сделанное подсудимым сознание будет им признано недостаточно разъясняющим дело, имеет право потребовать на основании 682 ст. Уст. Угол. Суд. судебного исследования, но предлагать вопросы подсудимому, хотя бы чрез председателя, прокурор права не имеет» (курсив наш. - Л. 3.).

2. Вопросы сведущим людям, согласно ст. 695 УСС, после представления ими заключения могут быть с разрешения председателя предложены как судьями и присяжными заседате- лями, так и сторонами. При этом вопросы сведущим людям предварялись приведением их к присяге по правилам приведения к присяге свидетелей.

В этом случае так же заметен приоритет в постановке вопросов лицу, выполнявшему по УСС функцию эксперта или специалиста, судом, но не сторонами.

3. Вопросы свидетелям (очевидцам в той или иной форме исследуемого события) регулировались комплексом норм УСС:

а) нормами ст. 718 допрос свидетеля начинался с предложением ему рассказать все то, что ему известно по делу, не примешивая обстоятельств посторонних и не повторяя слухов, не известно от кого исходящих;

б) правилами ст. 719 УСС устанавливалось, что после изложения свидетелем своего показания председатель суда предоставляет сторонам возможность задать свидетелю вопросы по всем предметам, которые каждая из них признает нужным выяснить;

в) диспозицией нормы ст. 720 УСС определялось, что вопросы свидетелю предлагаются сначала той стороной, по ссылке которой он призван к допросу, а потом противной стороной;

г) положениями ст. 721 УСС вводилось требование, по которому каждая сторона имела право предложить свидетелю вопросы не только о том, что он видел или слышал, но также и о тех обстоятельствах, которые доказывают, что он не мог показанного им ни видеть, ни слышать, или, по крайней мере, не мог видеть или слышать так, как о том свидетельствует;

д) В ст. 723 УСС содержались установления о том, что каждая сторона может предложить свидетелю вторичные вопросы в разъяснение ответов, данных на вопросы противной стороны.

В данной конструкции уголовно-процессуального закона обращает на себя внимание то, что в отличие от УПК РФ, в котором прежде описываются процессуальные результаты допросов (глава 10), а значительно дальше процессуальные средства - допросы (главы 23, $26,27,37)$ и с минимальным использованием термина «вопрос» в нормативном контексте диспозиций, в УСС вопрос является очевидным процессуальным средством ведения допроса. Вербальная процедура допроса, осуществляемая в устной форме, может осуществляться только через использование вопросов. Вопрос в допросе - тот минимальный фрагмент допроса, который определяет тип всего уголовного процесса, характер уголовно-процессуального закона. По этой причине вопрос по уголовно-процессуальному законодательству 
Российской империи есть неотъемлемая часть нормативного регулирования допросов, сама подвержена нормативному регулированию, как в части формулирования вопросов, так и их использования в допросе сторонами.

В качестве сравнения только что приведенных суждений относительно УСС с действующим уголовно-процессуальным законом укажем на следующие его положения:

1. В действующем УПК РФ присутствует правило о том, что при согласии подсудимого давать показания, первым его допрашивает сторона защиты, а потом сторона обвинения (ч. 1 ст. 275 УПК РФ). Суд задает вопросы подсудимому после его допроса сторонами (ч. 3 ст. 275 УПК РФ). Круг вопросов подсудимому не ограничивается, допускается, что и сторона обвинения будет задавать вопросы, которые соответствуют процессуальным задачам реализации функции обвинения, и суд будет задавать весь спектр вопросов, связанных с предметом доказывания по делу, замещая деятельность государственного обвинителя.

В УСС вопросы подсудимому, который не признает свою вину, не задавались. В противном случае он становится средством достижения процессуальных целей стороны обвинения. Вспоминая И. Канта, отметим, что правила закона Императора Александра II оказываются нравственными. Оберегая это положение, судебная практика кассационной инстанции (решение Уголовного кассационного департамента Правительствующего Сената № 298 от 27 февраля 1869 г. по делу князя Андронникова) отметила следующее: «Указывая на тех из участвующих в судопроизводстве лиц, которые непосредственно, или чрез председателя, могут допрашивать подсудимого, 684 ст. Уст. Угол. Суд. умалчивает о лицах прокурорского надзора; а так как нет оснований считать этот проблем случайным, то и следует заключить, что они в силу закона действительно лишены права обращаться с вопросом к подсудимому (курсив наш. - Л. 3.)».

Указанный в приведенном примере подсудимый не признавал вины. Это исключало его допрос (лицо, к которому можно адресовать вопросы) вообще в силу требований ст. 680 УСС, кроме того, вопросы исключались и от стороны обвинения, что предусматривалось нормами ст. 684 УСС.

Для современного правосознания (точнее для современной традиции) данная ситуация может представляться неожиданной. Однако, нормативная идея в этом очевидна. Вопросы сторон в состязательном типе процесса могут использоваться по отношению к подсудимому с соблюдением принципа favor defensionis. Сильная сторона, представляемая прокурором, имея в своем процессуальном арсенале досу- дебное производство, в целях уравнивания процессуальных средств сторон, не должна иметь право на вопросы (ответы) в ходе допроса к ядру стороны защиты - подсудимому, тем более, когда он не признает вину.

Современное российское законодательство в случае когда подсудимый не признает свою вину, но не отказывается от дачи показаний, допускает возможность его допроса (постановки вопросов) государственным обвинителем подсудимого. В этом случае не стоит придаваться правовой наивности, утверждая, что, задавая вопросы подсудимому, современный государственный обвинитель будет стараться действовать не оптимально и не эффективно, не задавая вопросов, связанных с процессуальной целью обвинения (стратегией обвинения) и процессуальными задачами допроса подсудимого (тактическими задачами допроса подсудимого). Конечно же, профессиональная деятельность государственного обвинителя будет толкать его на решения целей и задач реализуемой им функции обвинения.

2. В действующем уголовно-процессуальном законе допрос эксперта ведет сторона, задаются вопросы. Первой вопросы задает та сторона, по инициативе которой была назначена экспертиза (ч. 2 ст. 282 УПК РФ). В УСС модель допроса сведущего лица, как мы уже привели выше, иная. По правилу ст. 695 УСС вопросы сведущим лицам с разрешения председателя предлагались как судьями и присяжными заседателями, так и сторонами. Судьи короны и присяжные в технологии постановки вопросов указаны первыми. Данная процедура снижает степень процессуального средства как состязательного. Вопросы сведущим лицам, формируясь и используясь, прежде всего, судьями, реализуют функцию не сторон, а поиска какой-то истины посредством использования специальных знаний, схоже с реализацией функции разрешения дела.

Сегодня в теории уголовного процесса речь иногда заходит о состязательной судебной экспертизе, реализуемой сторонами, однако в законе воплощение этой идеи отсутствует. Более того, пока в действующем Федеральном законе от 31 мая 2001 г. № 73-Ф3 «0 государственной судебно-экспертной деятельности в Российской Федерации» в ст. 7 определен принцип независимости эксперта, в том числе и от сторон. Практика использования специальных знаний, воспринимаемая нами de visu, наводит на мысль, что состязательная судебная экспертиза (равное право сторон использовать данное процессуальное средство) не является реальностью как нормативного регулирования, так и, естественно, практики уголовного судопроизводства. 
Возможно, что, соответственно, реальности в части использования специальных знаний в конце XIX в. уголовно-процессуальная активность в формулировании и использовании вопросов сведущим лицам оставалась именно за судьями. Дать эту процессуальную возможность сторонам общество и законодательство не могло. Заимствование опыта прошлого законодательства в этой части как возможно, так и не возможно. Сегодня теория судебной экспертизы шагнула не просто далеко, а гигантски далеко вперед, что допускает установление равного процессуального режима использования специальных знаний сторонами. В то же время пример УСС в сравнении с действующим законодательством показывает возможные модели формулирования и использования вопросов субъектами уголовного процесса.

3) В ныне действующем законе имеется схожая с УСС касательно допроса свидетеля норма ч. 3 ст. 278 УПК РФ, которой определено, что первой свидетелю задает вопросы та сторона, по ходатайству которой он вызван в судебное заседание. В этом случае имеется некоторое презюмирование знания стороной тех сведений, о которых предполагается задавать вопросы. Связано это с тем, что всякое процессуальное средство, в том числе и вопросы стороны могут опираться на предварительно полученные в судебном следствии процессуальные результаты. В УСС эта проблема разрешена так называемым опережающим свободным рассказом свидетеля, урегулированным упомянутой ст. 718 УСС. Опережающий рассказ, естественно, определял содержание первых вопросов стороны свидетелю, создавая для них коммуникационную базу.

Также, в той же ч. 3 ст. 278 УПК РФ, определяющей такой порядок постановки вопросов, в соответствии с которым первой свидетелю задает вопросы та сторона, по ходатайству которой он вызван в судебное заседание, а потом судья, напоминающий правило ст. 720 УСС. Различия при этом обнаруживаются в том, что данная норма, по которой судья задает вопросы свидетелю после допроса сторонами, никак не ограничивает круг вопросов. Суд по действующему закону может задавать свидетелю все вопросы по делу, без их распределения по основным уголовно-процессуальным функциям. Законодатель же эпохи судебной реформы 1864 года, следуя реализуемому типу уголовного процесса, право суда на вопросы свидетелю ограничивает только дополнительными вопросами, то есть вопросами, задаваемыми судом в том случае, если ответами на вопросы сторон предмет показания не вполне объяснен (ст. 724 УСС). Уголовно-процессуальная активность, соответствующая состязательному типу процесса, в УСС доминирует. По действующему ныне закону, несмотря на установленный порядок, указанная доминанта активности не видится очевидной, потому что содержательные по форме следующие за вопросами сторон вопросы суда будут являться основными, связываться с предметом доказывания по делу, выполнением функции обвинения или защиты, не присущей суду, но не восполнением функции слабой стороны - favor defensionis. При этом речь идет не о досудебном производстве, а о судебном, в котором следование выбранному типу уголовного процесса видится обязательным.

Относительно же прав сторон, определенных в ст. 721, 723 УСС задавать любые вопросы, в том числе и вторично, необходимо отметить, что в действующем уголовно-процессуальном законе отсутствует запрет на постановку подобных вопросов, однако, присутствует возможность снятия вопросов стороны судьей, которые, по его мнению, не имеют отношения к делу. При прямом указании в законе возможности стороны на формулирование и использование вопросов, ответы на которые компрометируют свидетеля, возможности формулирования и использование вопросов, имеющих общее ядро, но различные редакции, обеспечивало бы реальную состязательность сторон в допросе, в том числе и перекрестном.

В итоге можно констатировать, что УСС содержит множество норм, регулирующих формулирование и использование вопросов сторонами в судебных допросах, которые могут быть использованы для совершенствования действующего уголовно-процессуального закона по состязательному типу.

Материал поступил в редакцию 2 марта 2014 г. 